\title{
Um modelo orientativo para a gestão municipal dos RCCs
}

\author{
A model for municipal management of CDW
}

\section{Maria da Paz Medeiros Fernandes Luiz Carlos Pinto da Silva Filho}

\section{Resumo}

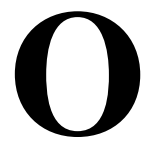

$\mathrm{s}$ resíduos da construção civil (RCCs) decorrem de perdas e desperdícios na construção, demolição, reforma e reparos de obras. Sua geração é elevada nos sistemas de produção correntes, organizados em linha com geração e descarte dos resíduos. Tentando minorar essa problemática, municipalidades brasileiras vêm experimentando a gestão diferenciada dos RCCs, notadamente após a Resolução n. 307/2002 (modificada pelas Resoluções ns. 348/2004, 431/2011 e 448/2012) do Conselho Nacional do Meio Ambiente (Conama) e a Lei n. 12.305/2010, que instituiu a Política Nacional dos Resíduos Sólidos (PNRS). Com o objetivo de auxiliá-las, o presente artigo, fruto de pesquisa de doutorado, apresenta um modelo orientativo para gestão municipal dos RCCs. Para a elaboração do modelo foi utilizada a metodologia dos sistemas flexíveis ou metodologia SSM (Soft Systems Methodology), adequada para situações reais e complexas como esta, que necessita reunir e sistematizar práticas, legislação, percepções, conceitos e interesses diversos dos atores envolvidos. O levantamento de dados foi realizado de 2009 a 2013 usando pesquisa bibliográfica, documentação indireta em oito municípios com boas práticas e documentação direta em Belo Horizonte e João Pessoa. Como resultado obteve-se um modelo cíclico que, através de suas diretrizes, estratégias e metas, fornece ajuda aos municípios brasileiros na incorporação de melhorias graduais e consistentes para esse desafio.

Palavras-chaves:Resíduos da Construção Civil. Gestão urbana. Solução participativa.
Maria da Paz Medeiros Fernandes

Instituto Federal de Educação, Ciência e Tecnologia da Paraíba João Pessoa - PB - Brasil

Luiz Carlos Pinto da Silva Filho Universidade Federal do Rio Grande

Porto Alegre - RS - Brasil

Recebido em 22/06/14 Aceito em 18/08/16

\begin{abstract}
Construction \& demolition waste $(C D W)$ is the waste generated during construction, demolition, renovation and repair works. The generation of $C D W$ is high in the current production systems, organized in line with the generation and disposal of waste materials. In an attempt to alleviate this problem, some municipalities in Brazil have started using differentiated management of CDW, notably after the issue of Resolution 307/2002 (modified by Res. 348/2004, 431/2011 and 448/2012) by the National Environment Council (Conselho Nacional do Meio Ambiente - Conama) and Law 12,305 /2010, which established the National Policy for Solid Waste (Política Nacional de Resíduos Sólidos PNRS). With the aim of helping municipalities to deal with the problem, this article, which results from a doctoral research study, presents a model for municipal management of CDW. Soft systems methodologies were used to map, organise and systematise different practices, legislation requirements, perceptions, concepts and the views of different actors involved with CDW in Brazil. The survey data was from 2009 to 2013, obtained through a literature review, indirect documentation in eight municipalities with good practices and direct documentation in the municipalities of Belo Horizonte and João Pessoa. The model was structured in 3 dimensions, which were subsequently detailed in strategies and targets. This model can help Brazilian municipalities to implement gradual and consistent improvements to deal with the challenge posed by $C D W$.

Keywords: Construction \& demolition waste. Urban management. Participatory solution.
\end{abstract}




\section{Introdução}

Os resíduos da construção civil (RCCs) provêm de perdas e desperdícios ocorridos na construção, demolição, reforma e reparos de obras. Geralmente são provenientes das próprias técnicas de construção civil utilizadas (ALGARVIO, 2009). Por serem decorrentes das perdas de diferentes materiais e processos construtivos, os RCCs possuem uma constituição heterogênea e de variadas dimensões (ZORDAN, 1997; ÂNGULO; JOHN, 2002; MÁLIA et al., 2011).

Em geral, esses resíduos ainda costumam ser descartados clandestinamente nas municipalidades brasileiras, o que ocasiona danos imensuráveis ao meio ambiente, à qualidade de vida da população e à saúde pública (SCHNEIDER; PHILIPPI, 2004; MÁLIA et al., 2011). Além disso, a limpeza e a coleta dessas deposições, juntamente com a saturação dos aterros licenciados (LINHARES; PEREIRA; RITTER, 2007), vêm ocasionando prejuízos financeiros e de planejamento urbano para os municípios.

A legislação específica para a gestão dos RCCs no Brasil começou a partir de 2002 com a Resolução 307 do Conselho Nacional do Meio Ambiente (Conama) (BRASIL, 2002). Essa resolução sofreu algumas modificações, com a Resolução 348/2004 (BRASIL, 2004), que classifica o amianto como resíduo perigoso da classe $\mathrm{D}$; a Resolução 431/2011 (BRASIL, 2011), que retira o gesso da classe $C$ (resíduos ainda inviáveis de reciclagem) e o coloca na classe B (resíduos recicláveis); e a Resolução 448/2012 (BRASIL, 2012), que se adéqua à Lei 12.305/2010 (BRASIL, 2010), que instituiu a Política Nacional de Resíduos Sólidos (PNRS).

A legislação brasileira traz diretrizes, critérios e procedimentos para a gestão dos RCCs através, prioritariamente, da não geração de resíduos e, hierarquicamente, da redução, da reutilização, da reciclagem (3Rs) e, para os resíduos ainda inviáveis de aplicação nas soluções anteriores, da correta destinação e disposição final, com a utilização de transportadoras e áreas de destino licenciadas.

Essa hierarquia para resíduos é respaldada internacionalmente (BARI et al., 2012) e estabelece um exercício da responsabilidade compartilhada entre o poder público, a iniciativa privada e a sociedade em geral, o que é prioritário para a efetiva gestão dos RCCs (PINTO, 2005; PUCCI, 2006; COUTO NETO, 2007; FERNANDES, 2013).

Com o advento da legislação específica, a situação começa a mudar nos municípios brasileiros, com as prefeituras buscando desenvolver e implantar planos municipais de gestão de RCC (PMGRCC) em conformidade com a legislação.

Entretanto, ainda são inúmeros os problemas decorrentes da falta de conhecimento e de efetivo planejamento para a gestão dos RCCs nos municípios (TESSARO et al., 2012), o que vem ocasionando uma gestão ineficaz, que pode até desestimular as demais municipalidades, que permanecem sem sequer ter iniciado esse planejamento.

Dessa forma, esse artigo, que é produto de uma pesquisa de doutorado, possui como objetivos: identificar boas práticas na gestão diferenciada dos RCCs de municípios brasileiros; conhecer a percepção dos diferentes atores envolvidos na gestão desses resíduos; e gerar um modelo para gestão municipal dos RCCs que possa ajudar os municípios brasileiros a resolver essa demanda premente.

\section{Método}

Para atingir os objetivos acima propostos, tomouse como base conceitual a metodologia de análise de sistemas complexos, conhecida como Metodologia dos Sistemas Flexíveis ou metodologia SSM (Soft Systems Methodology), proposta por Peter Checkland (CHECKLAND, 1981).

Essa metodologia foi escolhida por ser adequada a situações reais e complexas (FREITAS; COTA JÚNIOR; CHENG, 2008), que envolvem diversos atores em questões de ordem econômica, sanitária, social, ambiental e de governança (VALENÇA, 2004). Esse é o caso da gestão municipal dos RCCs em que as fronteiras e o problema são percebidos pelos atores envolvidos (esferas do poder público, grandes e pequenos geradores e transportadores dos RCCs, fabricantes, distribuidores, educadores, pesquisadores e população em geral) de diferentes e, muitas vezes, conflitantes pontos de vista.

A aplicação dessa metodologia visa levar a análise a um nível que permita a emersão e o exame das diferentes visões de mundo às quais os atores envolvidos possam aderir (CHECKLAND; POULTER, 2006) e contribuir para um ponto de ajuste em que todos cooperem para melhorias necessárias e factíveis.

Assim, a SSM faz o arrolamento (debate entre os envolvidos) das diferentes percepções a respeito da situação pesquisada, identificando os sistemas relevantes para a análise da situação e construindo 
um modelo conceitual que possa apresentar um ponto de "ajuste" entre os interesses conflitantes, de forma possibilitar mudanças que gerem melhorias na situação enfocada com a participação de todos.

\section{Amostragem}

Para a pesquisa foram selecionadas, a partir do levantamento bibliográfico e da consulta a pesquisadores da temática, municipalidades brasileiras que representassem casos distintos e significativos, a saber: pioneiras na gestão dos RCCs no Brasil - São Paulo (1991), Salvador (1992) e Belo Horizonte (1993); com boas práticas em 2011 na gestão dos RCCs - Belo Horizonte (MG), São José do Rio Preto (SP), Guarulhos (SP) e João Pessoa (PB); e pioneiras na reciclagem e uso dos RCCs pela iniciativa privada - Americana (SP) e Fortaleza (CE).

Essas municipalidades foram pesquisadas em relação à gestão dos RCCs através de levantamento bibliográfico e de pesquisa documental nos sites e na legislação ambiental das prefeituras e de empresas privadas.

Foi realizada também a coleta em fontes primárias nos municípios de João Pessoa (municipalidade de porte médio que possui em funcionamento desde 2007 a primeira área de reciclagem (AR) pública da região Nordeste do Brasil) e Belo Horizonte (com experiência em gestão diferenciada de RCC desde 1993), considerada a municipalidade modelo na gestão municipal dos RCCs no Brasil (COUTO NETO, 2007).

Por documentação direta foram pesquisadas nesses dois municípios a Autarquia Especial Municipal de Limpeza Urbana (Emlur), Área de Reciclagem do RCC inerte (AR), transportadoras, construtoras e sindicatos em João Pessoa; e a Secretaria Municipal de Limpeza Urbana (SLU), áreas de recebimento (pontos de entrega voluntária - PEVs, anteriormente denominados unidades de recebimento de pequenos volumes - URPVs, e a área de transbordo e triagem - ATT) e as três ARs conhecidas como estações de reciclagem em Belo Horizonte.

\section{Instrumentos e período da pesquisa}

O levantamento de dados foi realizado, de 2009 a 2013, através de arrolamento bibliográfico, consulta a profissionais e pesquisadores da área dos RCCs e pesquisa documental nas municipalidades pesquisadas.

A coleta direta inicial de dados foi realizada de setembro de 2009 a junho de 2010, em João Pessoa, com a utilização de entrevistas específicas, com questões abertas sobre a gestão dos RCCs (ao gestor público, aos transportadores, ao Sindicato da Indústria da Construção Civil - Sinduscon, ao Sindicato dos Trabalhadores da Indústria da Construção de João Pessoa - Sintricon e à população em geral) e aplicação de questionário a cerca de $20 \%$ das construtoras que em 2009 estavam oficialmente em atuação no município.

Os instrumentos de pesquisa aplicados inicialmente em João Pessoa, juntamente com a pesquisa bibliográfica, fundamentaram a elaboração do diagnóstico inicial e da formatação do problema em 2010 (etapas 1 e 2 da metodologia SSM respectivamente).

Em seguida, os resultados iniciais foram apresentados em congressos e eventos da área de gestão de resíduos e submetidos a outros pesquisadores. Definiram-se os sistemas relevantes (etapa 3) para solucionar a problemática, os quais, devido à adequadautilização da metodologia SSM, tornaram evidente o modelo conceitual para gestão dos RCCs (etapa 4), elaborado no primeiro semestre de 2011.

De posse do modelo conceitual foi necessário compará-lo com a situação real em municípios (etapa 5). Dessa forma, fez-se levantamento documental nas oito municipalidades escolhidas de 2011 a 2013. Também foi aplicada entrevista e feita observação direta com documentação fotográfica na AR de João Pessoa em 2009, 2010 e 2013. Em Belo Horizonte foram aplicadas entrevistas, questionários e observação sistemática com documentação fotográfica na SLU, em cinco dos trinta e dois PEVs existentes (lá chamados URPVs) e nas três ARs fixas (lá chamadas estações de reciclagem) no segundo semestre de 2011.

Em 2013 foi concluído o modelo proposto (etapa 6) ,tendo sido enviado para expoentes da área e para gestores, a fim de coletar críticas e sugestões, e, assim, aprimorar a versão definitiva do modelo (etapa 7), o qual é apresentado resumidamente neste artigo.

\section{Resultados}

A SSM, desenvolvida por Peter Checkland, possui sete estágios não obrigatoriamente sequenciais (CHECKLAND, 1981). Assim, para coletar e avaliar os dados utilizados na formatação do modelo, as sete etapas previstas na metodologia SSM foram executadas. 


\section{Etapas na formulação do modelo}

Na formulação do Modelo Orientativo para Gestão Municipal dos RCCs foram executadas as etapas, adaptadas da metodologia SSM, apresentadas a seguir.

\section{Etapa 1: investigação do problema real}

Para compreender a problemática da gestão dos RCCs e apresentar um diagnóstico da participação dos diferentes atores envolvidos foram utilizados o levantamento bibliográfico sobre a temática, a consulta a pesquisadores da área e a pesquisa direta preliminar realizada no município de João Pessoa.

Nessa municipalidade foram aplicados cinco modelos de entrevistas: órgão de limpeza urbana, sindicato dos empregadores, sindicato dos trabalhadores, transportadores, população em geral; e um questionário às construtoras, de forma a contemplar diversos atores envolvidos na gestão dos RCCs e a buscar conhecer as diferentes perspectivas e participações deles no objeto de estudo.
Os resultados foram apresentados em tabelas, que, juntamente com o levantamento bibliográfico, geraram a visualização do diagnóstico apresentado na Figura 1 (segunda etapa da metodologia SSM).

\section{Etapa 2: formataçãodo problema}

De posse do diagnóstico obtido na etapa anterior foi feita a formatação do problema (a situação do mundo real) utilizando a figura "rica" da metodologia SSM, conforme mostra a Figura 1, que retrata as diferentes perspectivas dos atores envolvidos na gestão dos RCCs e suas respectivas vinculações à estruturação do problema.

Observa-se que a teia de diferentes percepções e interesses constatada na pesquisa e mostrada na Figura 1 apresenta uma situação incontornável para a presente realidade de gestão de resíduos, devendo ser considerada a fim de que possa ser encontrado um equilíbrio inclusivo que proporcione uma solução eficiente e factível. Ressalta-se ainda que o ideal é que essas percepções e interesses evoluam a ponto de possibilitar a execução efetiva dos 3Rs.

Figura 1 - Figura "rica” da situação dos atores envolvidos na gestão dos RCC

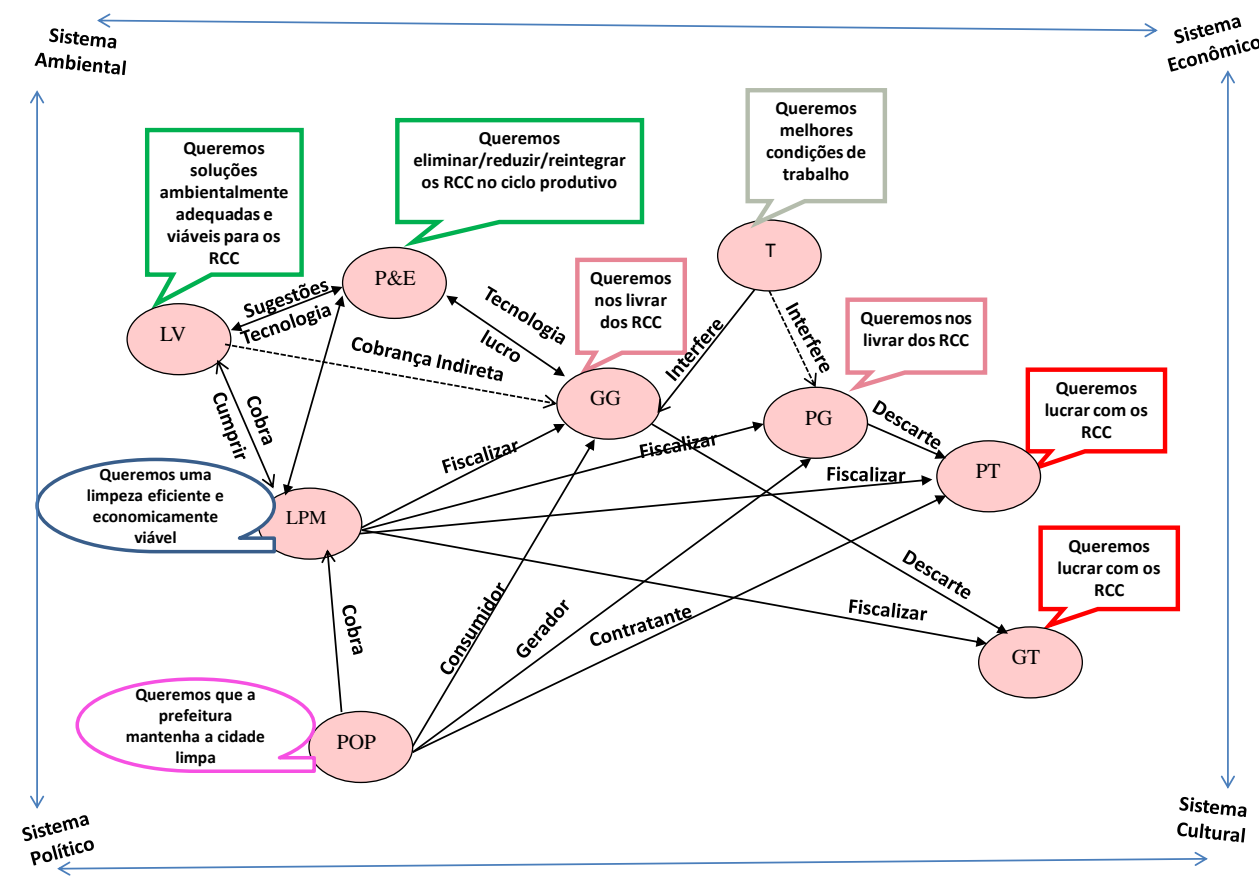

Nota: Legenda:

Órgão de limpeza pública municipal (LPM);

Legislação vigente (LV);

Grandes geradores (GG);

Pequenos geradores (PG);

Grandes transportadores (GT);

Pequenos transportadores (PT);

Trabalhadores da construção civil $(\mathrm{T})$;

Pesquisadores e estudiosos da área (P\&E); e

população em geral (POP). 
A figura "rica" agrega os diferentes atores envolvidos na gestão municipal dos RCCs e, embora a teia de relacionamentos entre eles possa variar de acordo com o grau de avanço ambiental e legislativo de cada país, possui um caráter universal em relação aos participantes da problemática e da solução.

\section{Etapa 3: definição dos sistemas relevantes}

Nesta terceira etapa foi utilizada a figura "rica" com as diferentes perspectivas dos atores envolvidos, apresentada na Figura 1, e o enriquecimento das ideias através da participação dos autores em congressos e eventos sobre a temática com a presença de estudiosos da área, visando definir o que era crucial para resolver o problema.

Assim, foi feita uma análise lógica e identificados três sistemas relevantes para o estudo, a saber: depositar os diferentes tipos de RCCs em locais licenciados; beneficiar o RCC classe A; e reinserilo no ciclo produtivo.

Fica evidente que a problemática da gestão dos RCCs é minorada com a reinserção do RCC classe A (inerte e passível de reutilização ou reciclagem para uso como agregado) no ciclo produtivo da construção civil, porque esse resíduo pode representar até $90 \%$ do RCC gerado no Brasil (ANGULO et al., 2002; MARCONDES, 2007).

\section{Etapa 4: construção do modelo conceitual}

Nesta etapa, considerando os sistemas relevantes identificados para uma efetiva gestão dos RCCs e suas ligações com o problema, e buscando um "ponto de ajuste" entre os interesses adversos, foi formatado um modelo conceitual (descrição dos meios necessários para que os sistemas representem a situação desejada), em que se propõem melhorias na problemática estudada.

A Figura 2 apresenta o modelo conceitual com as três diretrizes (sistemas relevantes identificados na etapa 3) interagindo com a indústria da construção civil (ICC). A dinâmica cíclica do modelo conceitual proposto visa a uma acomodação entre os diversos atores e seus interesses, muitas vezes conflitantes.

\section{Etapa 5: comparação do modelo conceitual com a situação real}

Nesta quinta etapa foi comparado o modelo conceitual proposto na etapa 4 (Figura 2) com a situação problema descrita na etapa 2 (figura "rica"), visando realizar as complementações e os ajustes necessários para as mudanças desejáveis e viáveis, ou seja, buscou-se o "como" realizar o proposto no modelo conceitual.

Para a comparação entre a realidade (mundo real) e o modelo conceitual proposto (mundo de sistemas) foi realizado levantamento documental em municípios brasileiros (São Paulo, Salvador, Belo Horizonte, São José do Rio Preto, Guarulhos, João Pessoa, Americana e Fortaleza) com gestão diferenciada (PINTO, 1999) dos RCCs, e foi feita pesquisa direta em Belo Horizonte e em João Pessoa. Em Belo Horizonte foram aplicadas entrevistas à SLU, em cinco PEVs (dos 32 existentes) e nas três ARs fixas do município em 2011. Realizou-se a visita a ATT privada em funcionamento no município, na qual foram feitas observação e coleta de dados básicos.

Figura 2- Modelo conceitual da gestão municipal dos RCCs

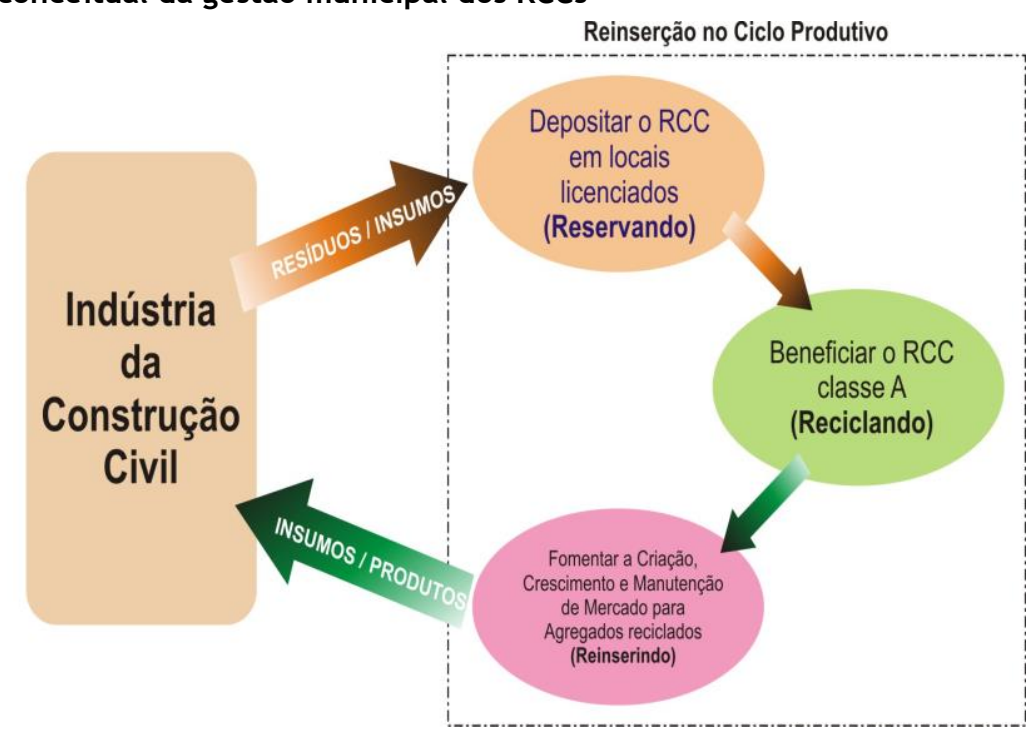


Também foram usadas amostras instantâneas, aplicando-se entrevistas com empregados e carroceiros que estavam presentes durante a visita aos cinco PEVs, e a cerca de $20 \%$ dos funcionários das três ARs de Belo Horizonte.

Em João Pessoa foram aplicadas entrevistas na Emlur e na AR fixa da municipalidade. Tanto nos PEVs estudados quanto nas ARs também foi utilizada a observação direta com documentação fotográfica como instrumento de pesquisa.

Ressaltando que a metodologia SSM é cíclica nesta etapa 5, as etapas 1 e 2 foram enriquecidas, e algumas definições nos sistemas relevantes (etapa 3) foram aprimoradas a fim de identificar as mudanças viáveis, factíveis e relevantes para melhorar a situação-problema. O Quadro 1 apresenta resumidamente a situação dos três sistemas relevantes nas municipalidades estudadas: reservando (colunas 3 a 5); reciclando (colunas 3 e 6 ); e reinserindo (colunas 3 e 7).

Avaliando a situação dos sistemas relevantes em cada municipalidade estudada, observa-se que os maiores avanços estão no reservando, a saber: São Paulo, que inicialmente não fez a rede de coleta, evoluiu para um amplo investimento em PEVs e vem incentivando a implantação de ATTs privadas; Belo Horizonte possui experiência consolidada em PEVs e ATTs privadas insuficientes; Guarulhos e São José do Rio Preto possuem redes de PEVs consolidadas e ATTs privadas em expansão; e as demais municipalidades pesquisadas vêm implantando ou planejam fazê-lo em breve, merecendo destaque as ATTs privadas de Americana e Fortaleza (junto com as ARs).

Em relação ao sistema relevante reciclando, a municipalidade pioneira foi São Paulo, entretanto a AR não se consolidou; Belo Horizonte possui a experiência consolidada com ARs públicas em pleno funcionamento desde 1995; São José do Rio Preto e Guarulhos são exemplos desde 2004; Americana possui uma experiência ímpar, onde a iniciativa privada vem reciclando quase todo o RCC produzido na municipalidade; e no Nordeste temos dois exemplos importantes, em João Pessoa a primeira $\mathrm{AR}$ pública da região, que funciona desde 2008, e em Fortaleza, uma AR privada que vem funcionando desde 1997.

Fechando o ciclo, nota-se que, no geral, as municipalidades estudadas buscam dar o exemplo do sistema relevante reinserindo mediante a utilização de agregados reciclados nas obras públicas, entretanto existe a necessidade de que a iniciativa privada assuma esse compromisso, para fortalecer esse mercado, que deve ser cada vez mais respaldado por pesquisas científicas.
Portanto, foi positivo o resultado da comparação do conceitual com o real, uma vez que nos municípios pesquisados os três sistemas relevantes, que juntamente com a indústria da construção civil formam o modelo conceitual, estão presentes sejam em nível de planejamento, sejam recém-implementados ou já consolidados, conforme mostra o Quadro 1. Dessa forma, as municipalidades pesquisadas contribuíram para a elaboração das estratégias do modelo propostas na etapa 6.

\section{Etapa 6: mudanças convenientes e factíveis}

Após a comparação do modelo conceitual (Figura 2) com a realidade descrita na etapa 2 (Figura 1), foi possível propor as mudanças necessárias e passíveis de ser implantadas para transformar positivamente a situação estudada. Assim, nesta etapa foi estabelecido o modelo proposto para gestão municipal dos RCCs, tendo sido elaboradas e sugeridas as estratégias e ações factíveis para melhorar a situação abordada e as metas para avaliar e aperfeiçoar o desempenho da gestão.

\section{Etapa 7: tomada de ação visando melhorar a situação-problema}

Nesta etapa podem ser implantadas as ações julgadas cruciais para as mudanças desejadas. Entretanto, essa fase não foi completamente desenvolvida devido a limitações políticas (necessidade de um município que implantasse integralmente o modelo definido) e, principalmente, temporais (tempo para maturação das mudanças e manifestação dos resultados) já previstas na pesquisa.

Dessa forma, nesta sétima etapa foi feito o envio do modelo proposto para ser examinado por especialistas da área de gestão dos RCCs, agregando as contribuições deles para a formatação do modelo definido para a melhoria da situação estudada.

Nesse sentido, foram consultados quatro pesquisadores da temática, sendo três acadêmicos da área de aproveitamento de RCC e um consultor da área de resíduos. Os pesquisadores consideraram o modelo proposto adequado, com o ineditismo de buscar a acomodação entre os diferentes interesses dos atores envolvidos na gestão dos RCCs. Também fizeram sugestões em relação a algumas ações propostas, que, depois de avaliadas, foram incorporadas à versão ratificada. Após, como passo final da formatação, foi feito o envio do modelo na versão ratificada, para apreciação de gestores públicos da área de gestão de resíduos de dois municípios (um de grande e outro de médio porte). 
Quadro 1 - Sistemas relevantes nas municipalidades pesquisadas

\begin{tabular}{|c|c|c|c|c|c|c|}
\hline & Histórico da gestão dos RCCs & $\begin{array}{l}\text { Plano de } \\
\text { gestão dos } \\
\text { RCCs }\end{array}$ & $\begin{array}{l}\text { PEVs } \\
(2012)\end{array}$ & $\begin{array}{l}\text { ATTs } \\
(2012)\end{array}$ & $\begin{array}{l}\text { ARs } \\
\text { Fixas } \\
(2012)\end{array}$ & $\begin{array}{l}\text { Uso de } \\
\text { Agregados } \\
\text { Reciclados }\end{array}$ \\
\hline $\begin{array}{l}\text { São Paulo } \\
11.253 .503 \\
\text { habitantes } \\
(2010)\end{array}$ & $\begin{array}{l}\text { Inaugurou em } 1991 \text { a primeira AR do } \\
\text { Hemisfério Sul, desativada por falta de } \\
\text { uma rede de recepção com PEVs e ATTs. } \\
\text { Em } 2012 \text { é exemplo na implementação de } \\
\text { PEVs e tem investido em ATTs e na } \\
\text { fiscalização de depósitos clandestinos. }\end{array}$ & $\begin{array}{l}\text { Elaborado em } \\
\text { 2005, Lei } \\
\text { 14.803/2008. }\end{array}$ & $\begin{array}{l}\text { Cinqüenta } \\
\text { e cinco. }\end{array}$ & $\begin{array}{l}\text { Cinco } \\
\text { Privadas. }\end{array}$ & $\begin{array}{l}\text { Duas } \\
\text { Privadas } \\
(2010, \\
\text { pequeno } \\
\text { Porte) }\end{array}$ & $\begin{array}{l}\text { Uso em } \\
\text { obras } \\
\text { públicas a } \\
\text { partir de } \\
2006 .\end{array}$ \\
\hline $\begin{array}{l}\text { Salvador } \\
2.675 .676 \\
\text { habitantes } \\
(2010)\end{array}$ & $\begin{array}{l}\text { Um dos municípios pioneiros em } \\
\text { planejamento de gestão diferenciada dos } \\
\text { RCCs. Entretanto, não houve implantação } \\
\text { do proposto e em } 2012 \text { existiam poucos e } \\
\text { precários PEVs, ATTs e aterros de inertes. }\end{array}$ & $\begin{array}{l}\text { Elaborado em } \\
\text { 1992,depois } \\
\text { em } 1997 \text { e } \\
\text { pelo Decreto } \\
12.133 / 98 .\end{array}$ & Quatro. & $\begin{array}{l}\text { Pequenas } \\
\text { e } \\
\text { privadas. }\end{array}$ & - & $\begin{array}{l}\text { Não } \\
\text { informado. }\end{array}$ \\
\hline $\begin{array}{l}\text { Belo } \\
\text { Horizonte } \\
2.375 .151 \\
\text { habitantes } \\
(2010)\end{array}$ & $\begin{array}{l}\text { Município exemplo devido a implantação } \\
\text { da gestão diferenciada dos RCCs de } \\
\text { maneira pioneira e continuada desde } \\
\text { 1993. Em } 2012 \text { possuía } 32 \text { PEVs (alguns } \\
\text { desde 1995), três ARs públicas (em } \\
\text { funcionamento desde } 1995,1996 \text { e 2006) } \\
\text { consolidadas e duas ATTs privadas. }\end{array}$ & $\begin{array}{l}\text { Programa em } \\
\text { 1993. Lei } \\
\text { 10.552/2012. }\end{array}$ & $\begin{array}{l}\text { Trinta e } \\
\text { dois. }\end{array}$ & $\begin{array}{l}\text { Duas } \\
\text { privadas. }\end{array}$ & $\begin{array}{l}\text { Três } \\
\text { públicas }\end{array}$ & $\begin{array}{l}\text { Uso em } \\
\text { obras } \\
\text { públicas a } \\
\text { partir de } \\
1995 .\end{array}$ \\
\hline $\begin{array}{l}\text { SJRP } \\
408.258 \\
\text { habitantes } \\
(2010)\end{array}$ & $\begin{array}{l}\text { Municipalidade exemplo de gestão } \\
\text { diferenciada dos RCCs a partir da Res. } \\
\text { 307/2002. Tem uma AR pública em } \\
\text { parceria com transportadores desde } 2005 \\
\text { e experiência consolidada em PEVs com } \\
\text { dezenove em funcionamento em } 2012 \text {. } \\
\text { Também é exemplo na busca de parcerias } \\
\text { intermunicipais com o setor privado e no } \\
\text { aprimoramento da fiscalização. }\end{array}$ & $\begin{array}{l}\text { Lei } \\
9.393 / 2004 \text { e } \\
\text { Decreto } \\
12.765 / 2005 .\end{array}$ & Dezenove. & $\begin{array}{l}\text { Pequenas } \\
\mathrm{e} \\
\text { privadas. }\end{array}$ & $\begin{array}{l}\text { Uma } \\
\text { pública. }\end{array}$ & $\begin{array}{l}\text { Uso em } \\
\text { obras e } \\
\text { serviços } \\
\text { públicos a } \\
\text { partir de } \\
2005 .\end{array}$ \\
\hline $\begin{array}{l}\text { Guarulhos } \\
1.221 .979 \\
\text { habitantes } \\
(2010)\end{array}$ & $\begin{array}{l}\text { Município exemplo de gestão diferenciada } \\
\text { dos RCCs a partir da Res. 307/2002. } \\
\text { Em } 2012 \text { possuía quinze PEVs, duas ARs } \\
\text { (uma de economia mista e uma privada), } \\
\text { seis ATTs e três Aterros de inertes. } \\
\text { Pioneiro em 2011 na inserção dos } \\
\text { requisitos da PNRS através do Plano } \\
\text { Diretor de Resíduos Sólidos (PDRS). }\end{array}$ & $\begin{array}{l}\text { Elaborado em } \\
2005 . \\
\text { E o PDRS } \\
\text { em } 2011 .\end{array}$ & Quinze. & $\begin{array}{l}\text { Seis } \\
\text { privadas. }\end{array}$ & $\begin{array}{l}\text { Uma } \\
\text { mista e } \\
\text { uma } \\
\text { privada }\end{array}$ & $\begin{array}{l}\text { Uso em } \\
\text { serviços } \\
\text { públicos } \\
\text { desde } \\
2005 \text {. } \\
\text { Desconto } \\
\text { no IPTU a } \\
\text { partir de } \\
2011 .\end{array}$ \\
\hline $\begin{array}{l}\text { João } \\
\text { Pessoa } \\
723.515 \\
\text { habitantes } \\
(2010)\end{array}$ & $\begin{array}{l}\text { Municipalidade que vem buscando a } \\
\text { gestão diferenciada dos RCCs a partir da } \\
\text { Res. 307/2002. Possui uma AR pública } \\
\text { consolidada desde } 2007 \text { e ATTs e Aterros } \\
\text { privados de pequeno porte. } \\
\text { Em } 2012 \text { ainda não tinha nenhum PEV. }\end{array}$ & $\begin{array}{l}\text { Lei } \\
11.176 / 2007 .\end{array}$ & - & $\begin{array}{l}\text { Pequenas } \\
\mathrm{e} \\
\text { privadas. }\end{array}$ & $\begin{array}{l}\text { Uma } \\
\text { pública. }\end{array}$ & $\begin{array}{l}\text { Uso em } \\
\text { obras e } \\
\text { serviços } \\
\text { públicos a } \\
\text { partir de } \\
2008 .\end{array}$ \\
\hline $\begin{array}{l}\text { Americana } \\
210.638 \\
\text { habitantes } \\
(2010)\end{array}$ & $\begin{array}{l}\text { Município exemplo de gestão diferenciada } \\
\text { dos RCCs a partir da iniciativa privada. } \\
\text { Possui uma AR privada consolidada que } \\
\text { beneficia cerca de } 80 \% \text { do RCC classe A } \\
\text { da municipalidade e uma ATT privada. } \\
\text { PEVs sendo implantados a partir de } 2010 \text {. }\end{array}$ & $\begin{array}{l}\text { Decreto } \mathrm{n}^{\circ} \\
7.730 / 2008 .\end{array}$ & Dois. & $\begin{array}{l}\text { Uma } \\
\text { privada. }\end{array}$ & $\begin{array}{l}\text { Uma } \\
\text { privada. }\end{array}$ & $\begin{array}{l}\text { Uso em } \\
\text { obras e } \\
\text { serviços } \\
\text { públicos a } \\
\text { partir de } \\
2008 .\end{array}$ \\
\hline $\begin{array}{l}\text { Fortaleza } \\
2.452 .185 \\
\text { habitantes } \\
(2010)\end{array}$ & $\begin{array}{l}\text { Experiência consolidada de uma AR } \\
\text { privada em funcionamento desde } 1997 . \\
\text { PEVs sendo implantados a partir de } 2010 \text {. }\end{array}$ & $\begin{array}{l}\text { Elaborado em } \\
2006 .\end{array}$ & Dois. & $\begin{array}{l}\text { Uma } \\
\text { privada. }\end{array}$ & $\begin{array}{l}\text { Uma } \\
\text { privada. }\end{array}$ & $\begin{array}{l}\text { Uso em } \\
\text { obras } \\
\text { desde } \\
2004 .\end{array}$ \\
\hline
\end{tabular}

Ambos os gestores inicialmente consideraram o modelo muito amplo e de difícil execução pelo poder municipal (um número grande de estratégias), mas depois da análise (levaram-se 15 dias para a avaliação do modelo) opinaram que, embora fosse bastante extenso, o detalhamento proposto seria necessário para uma efetiva gestão dos RCCs.

Os gestores fizeram sugestões em relação à simplificação de algumas ações e solicitaram maior ênfase na formação de parcerias entre as três 
esferas do poder público (municipal, estadual e federal) e entre o poder público e o setor privado. Deveriam ficar, segundo eles, bem definidas e explicitadas as atribuições de cada ator envolvido, a fim de viabilizar a execução do modelo.

Assim, com base nos resultados (opinião e contribuições de pesquisadores, consultores e gestores públicos acerca do modelo proposto), foi consolidada a versão definitiva do modelo para gestão municipal dos RCCs, apresentada resumidamente a seguir.

\section{Estrutura do modelo orientativo definido}

O modelo conceitual apresentado na Figura 2 é estruturado com três diretrizes, que se constituem nas linhas reguladoras que fundamentam o modelo definido. As três diretrizes se articulam, são interdependentes e compostas de estratégias ou conjuntos de decisões que moldam o caminho escolhido para seu cumprimento (Figura 3).

A Diretriz 1 - Depositar o RCC em locais licenciados - é composta de dez estratégias (apresentadas na Figura 4), que são avaliadas por quatro metas (indicadas na Figura 5). A Diretriz 2 - Beneficiar o RCC classe A - é composta de cinco estratégias (referidas na Figura 6), cujo desempenho é indicado por quatro metas (apresentadas na Figura 7); e a Diretriz 3 Fomentar a criação, o crescimento e a manutenção de mercado para agregados reciclados - é composta de quatro estratégias (expostas na Figura 8), avaliadas por quatro metas (apresentadas na Figura 9), conforme mostra a Figura 3.

Observa-se que a Diretriz 1 - Depositar o RCC em locais licenciados - representa uma necessidade de qualquer municipalidade brasileira, que a partir de um diagnóstico inicial (avaliação qualitativa e quantitativa) dos RCCs deve solucionar adequadamente a problemática do que fazer com esses resíduos (PINTO, 2005; SCREMIN, 2007; BERNARDES et al., 2008; TEIXEIRA, 2010; TESSARO et al., 2012; FERNANDES, 2013), respeitando as peculiaridades das quatro classes de RCC (BRASIL, 2002).

Assim, aparentemente as estratégias da Diretriz 1 se constituem em um plano de gestão diferenciada dos RCCs. Entretanto, colocar em prática apenas essa diretriz levaria ao rápido esgotamento das áreas licenciadas (geralmente escassas na zona urbana) e não resolveria o problema de eficácia na gestão dos RCCs.

Dessa forma, uma vez coletado e reservado, é importante que o RCC classe A (BRASIL, 2002) seja reutilizado com retorno imediato ao ciclo produtivo ou reciclado, transformando-se em agregado reciclado por peneiramento e/ou britagem (NUNES, 2004; MIRANDA, 2005; PASQUALOTTO FILHO et al., 2007; CUNHA, 2007), conforme explicita a Diretriz 2.

Figura 3- As diretrizes do modelo com suas respectivas estratégias e metas

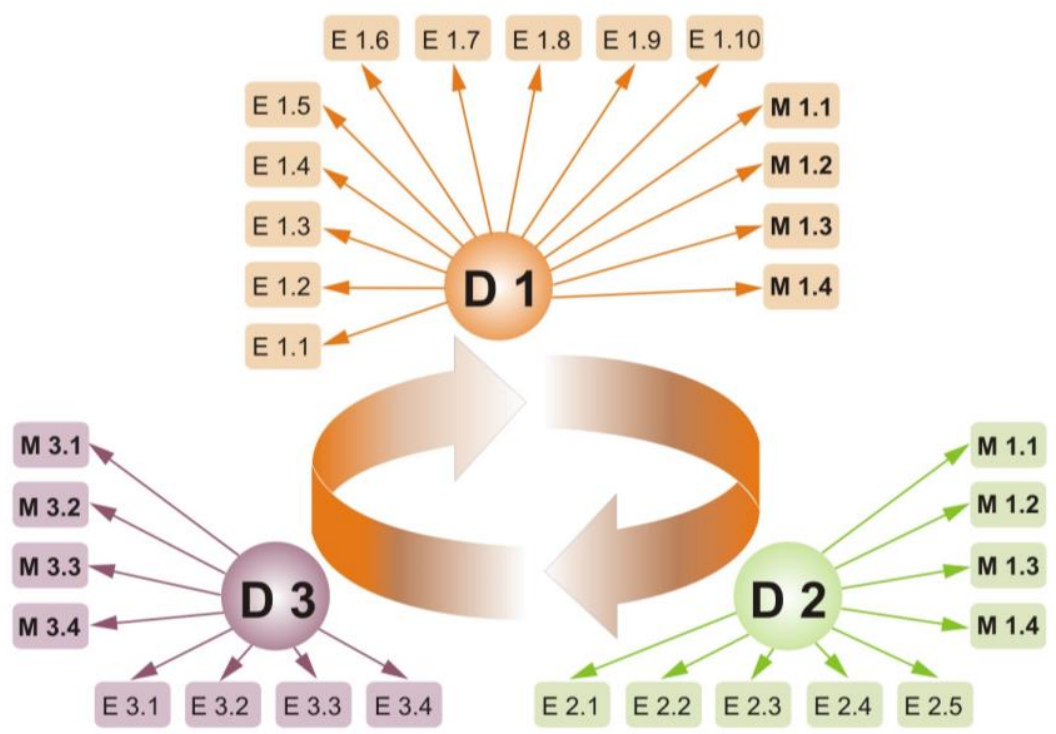

28 Fernandes, M. da P. M.; Silva Filho, L. C. P. da 
Após o beneficiamento do RCC classe A (Diretriz 2 ), existe a necessidade do fortalecimento do mercado para os agregados reciclados produzidos (REMBISKI, 2012; SOBRAL, 2012). Assim, a Diretriz 3 fecha o ciclo para reinserção do RCC classe A no processo produtivo da indústria da construção civil (ICC).

Nesse sentido, ressalta-se que a criação e manutenção do mercado dos agregados reciclados é condição para que a gestão municipal de RCC seja eficaz e duradoura (JOHN, 2000; MARCONDES, 2007). Esse mercado se estabelecerá mediante a garantia de qualidade, suprimento e ganhos financeiros com a produção e uso desses produtos. Portanto, juntas, as três diretrizes formam um ciclo de reinserção do RCC classe A no processo produtivo da ICC.

A sustentabilidade financeira do modelo orientativo definido se dá através da diminuição das deposições clandestinas e dos custos decorrentes de sua correção; do exercício crescente da responsabilidade de cada gerador (grande ou pequeno) na redução, segregação, reaproveitamento e destinação adequada; de uma efetiva participação da iniciativa privada no beneficiamento e uso de agregados reciclados, o que fortalece esse mercado e torna-o competitivo; e da aplicação de multas e penalidades para os indisciplinados (o poluidor paga pela reparação do dano).

\section{Detalhamento da Diretriz 1}

A Diretriz 1 é formada por um conjunto de medidas que visam à extinção das deposições clandestinas, causadoras de danos ambientais, sanitários, econômicos e estéticos, composta de dez estratégias que buscam desde o combate à deposição clandestina até a destinação adequada aos diferentes tipos de RCC. Prima, ainda, pela inclusão social, pela redução da geração e pelo amplo processo educativo dos atores envolvidos.

As dez estratégias propostas envolvem a criação de unidades descentralizadas para captação dos RCCs do grande gerador (áreas de transbordo e triagem dos RCCs e volumosos - ATTs) e do pequeno gerador (PEVs), aterro(s) para reservação do RCC classe A, reciclagem do RCC classe B (papel, papelão, plástico, vidro e metais) por cooperativas, segregação e destinação do gesso (para reciclagem) e de componentes das classes $\mathrm{C}$ e D por logística reversa, e disposição final dos rejeitos dos RCCs em aterros específicos, além do envolvimento da comunidade desde o mapeamento da deposição clandestina até a educação continuada, que fomenta o exercício da responsabilidade de cada gerador (Figura 4).

A Diretriz 1 possui quatro indicadores de desempenho quantificáveis, na forma das metas $1 \mathrm{~A}$ a $1 \mathrm{D}$, que devem ser aferidos periodicamente a fim de verificar o nível de cumprimento das dez estratégias da Diretriz 1, apresentadas na Figura 4, e proporcionar o aprimoramento contínuo do sistema de gestão. A Figura 5 apresenta essas metas e a relação de cada meta com as estratégias referidas.

\section{Figura 4 - Estratégias da Diretriz 1 do modelo definido}

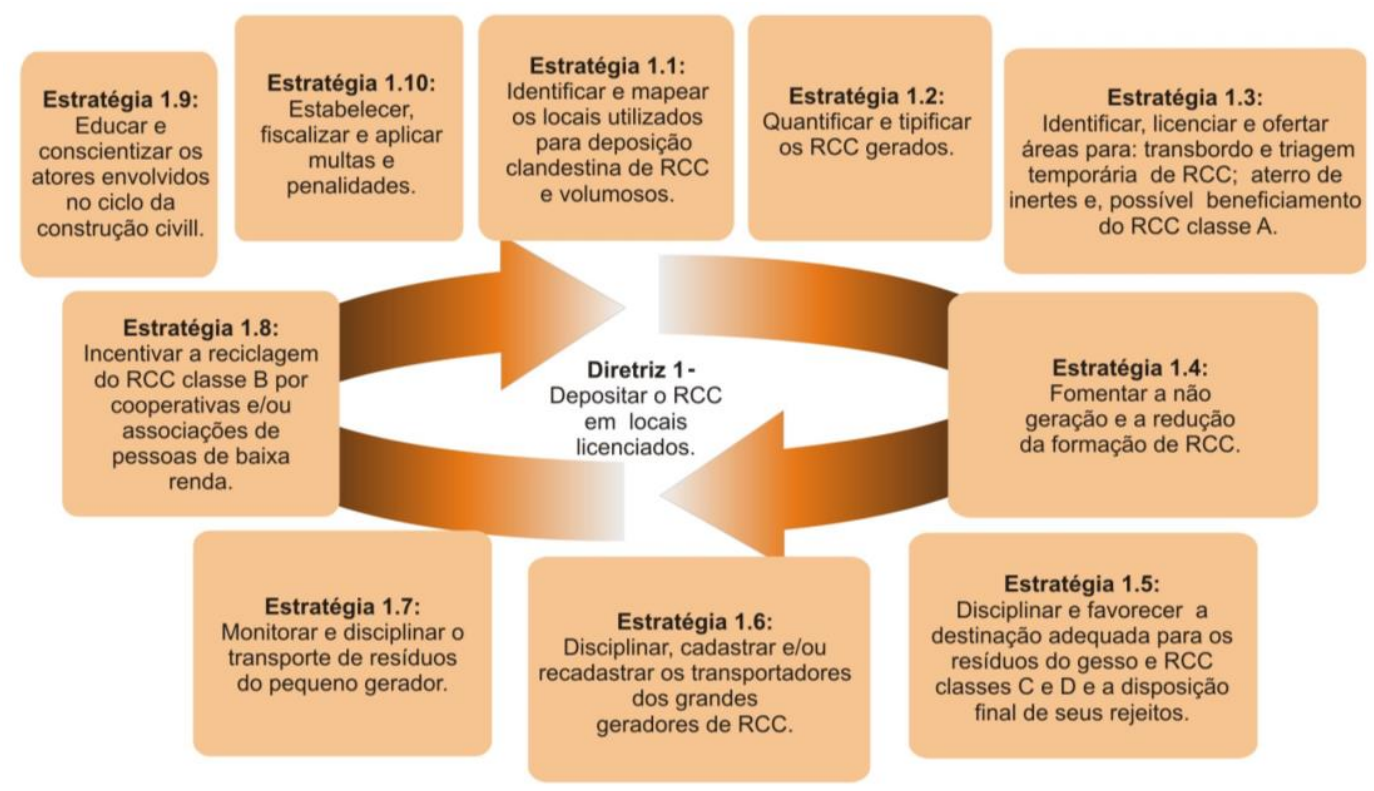


Figura 5- Aferição das estratégias por metas na Diretriz 1 do modelo

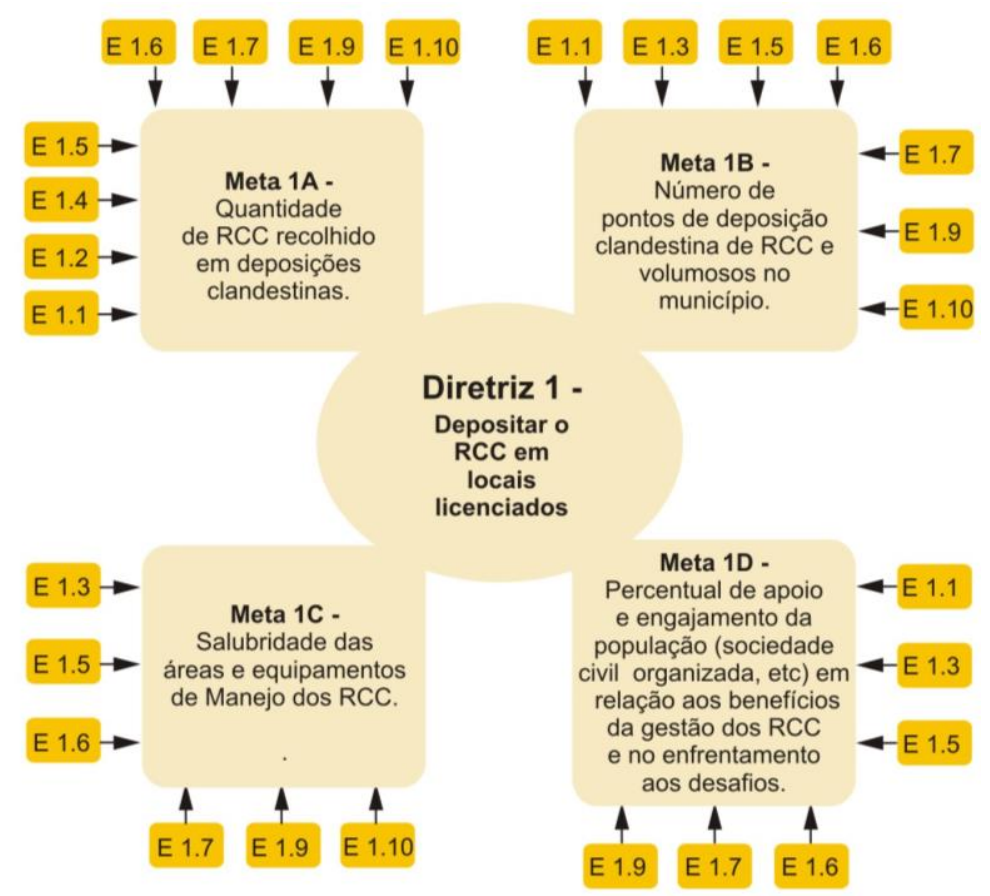

Vale salientar que para a Estratégia 1.4 a meta ou indicador prioritário deve ser a redução do RCC por metro quadrado $\left(\mathrm{m}^{2}\right)$ construído, entretanto isso se dá no nível de controle interno do próprio gerador, pois para a municipalidade esse indicador dificilmente seria real devido à falta de controle do número de edificações e do total de área construída no município, decorrente das construções e deposições clandestinas ainda não debeladas no Brasil.

\section{Detalhamento da Diretriz 2}

A Diretriz 2 - Beneficiar o RCC classe A estabelece o beneficiamento do RCC classe A, o qual, desde que devidamente segregado, se transforma facilmente em matéria-prima a ser reutilizada ou reciclada (agregados reciclados por peneiramento e/ou britagem) para uso na indústria da construção civil.

Essa diretriz é composta de cinco estratégias, que visam desde a segregação na origem até a entrada do capital privado nas ATTs e nas ARs (Figura 6).

Assim, tem-se um aprimoramento da gestão municipal do RCC, com o beneficiamento do resíduo classe $\mathrm{A}$, evitando a escassez de áreas para reserva (guarda e acumulação do RCC inerte) e possibilitando a reinserção desse resíduo no ciclo produtivo.

Essa diretriz possui as metas de $2 \mathrm{~A}$ a $2 \mathrm{D}$ como indicadores de desempenho quantificáveis, que devem ser aferidos periodicamente, a fim de verificar o nível de cumprimento das cinco estratégias da Diretriz 2, apresentadas na Figura 6, e proporcionar o aprimoramento contínuo do sistema de gestão. A Figura 7 mostra a relação de cada meta com as estratégias mencionadas.

A eficaz reciclagem do $\mathrm{RCC}$ classe A fomentará novos hábitos laborais e de consumo e novas práticas de projeto visando à demolição seletiva (desmontagem), à durabilidade dos materiais e ao consumo de materiais reciclados. Assim, a Diretriz 2 traz um avanço na sustentabilidade ambiental e econômica, o que possibilita o autofinanciamento da gestão e uma participação ativa da iniciativa privada no negócio.

\section{Detalhamento da Diretriz 3}

A Diretriz 3 - Fomentar a criação, crescimento e manutenção de mercado para agregados reciclados - possibilita a eficácia do sistema de gestão de RCC, com a preservação dos recursos naturais (minimização da extração de jazidas virgens) e o crescimento e a manutenção do mercado de agregados reciclados. Esse mercado fortalecido dará sustentação a toda a gestão de RCC, tornando-a economicamente atrativa como negócio $\mathrm{e}$, portanto, praticamente imune às mudanças dos gestores públicos. A Figura 8 mostra as quatro estratégias que compõem a Diretriz 3.

Essa diretriz possui como indicadores de desempenho as metas $3 \mathrm{~A}$ a $3 \mathrm{D}$, os quais devem ser aferidos periodicamente a fim de verificar o nível 
de cumprimento das quatro estratégias da Diretriz 3, apresentadas na Figura 8, e proporcionar o aprimoramento contínuo. A Figura 9 mostra a relação de cada meta com as estratégias da Diretriz 3.

É importante ressaltar que, embora as Diretrizes 1, 2 e 3, com suas respectivas estratégias e ações, sejam de uma lógica sequencial, o processo não deve ficar engessado caso na municipalidade haja dificuldade imediata de realizar alguma etapa.

\section{Proposição de cenários futuros com a aplicação do modelo definido}

O Modelo Orientativo para Gestão Municipal dos RCCs definido possibilita melhorias importantes para as municipalidades brasileiras e permite, com o passar do tempo, que seja efetuado um acompanhamento e validação dos critérios e indicadores propostos.

Figura 6 - Estratégias da Diretriz 2 do modelo definido

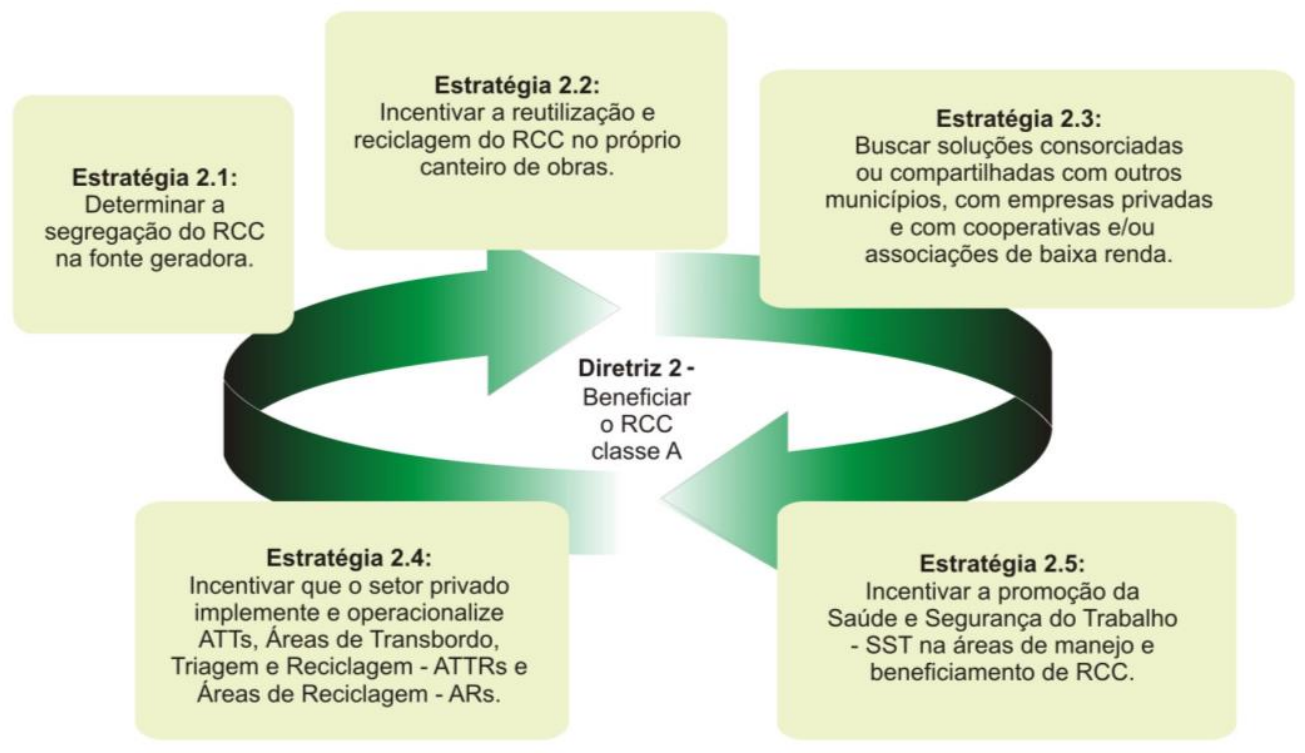

Figura 7 - Aferição das estratégias por metas na Diretriz 2 do modelo

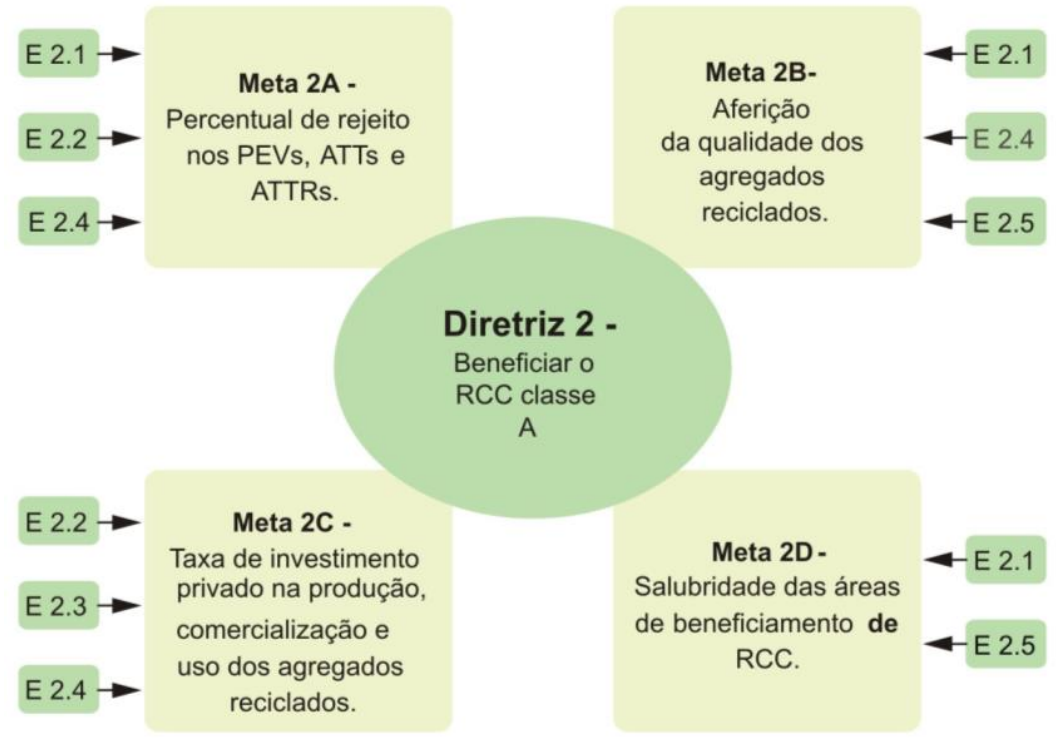


Figura 8 - Estratégias da Diretriz 3 do modelo definido

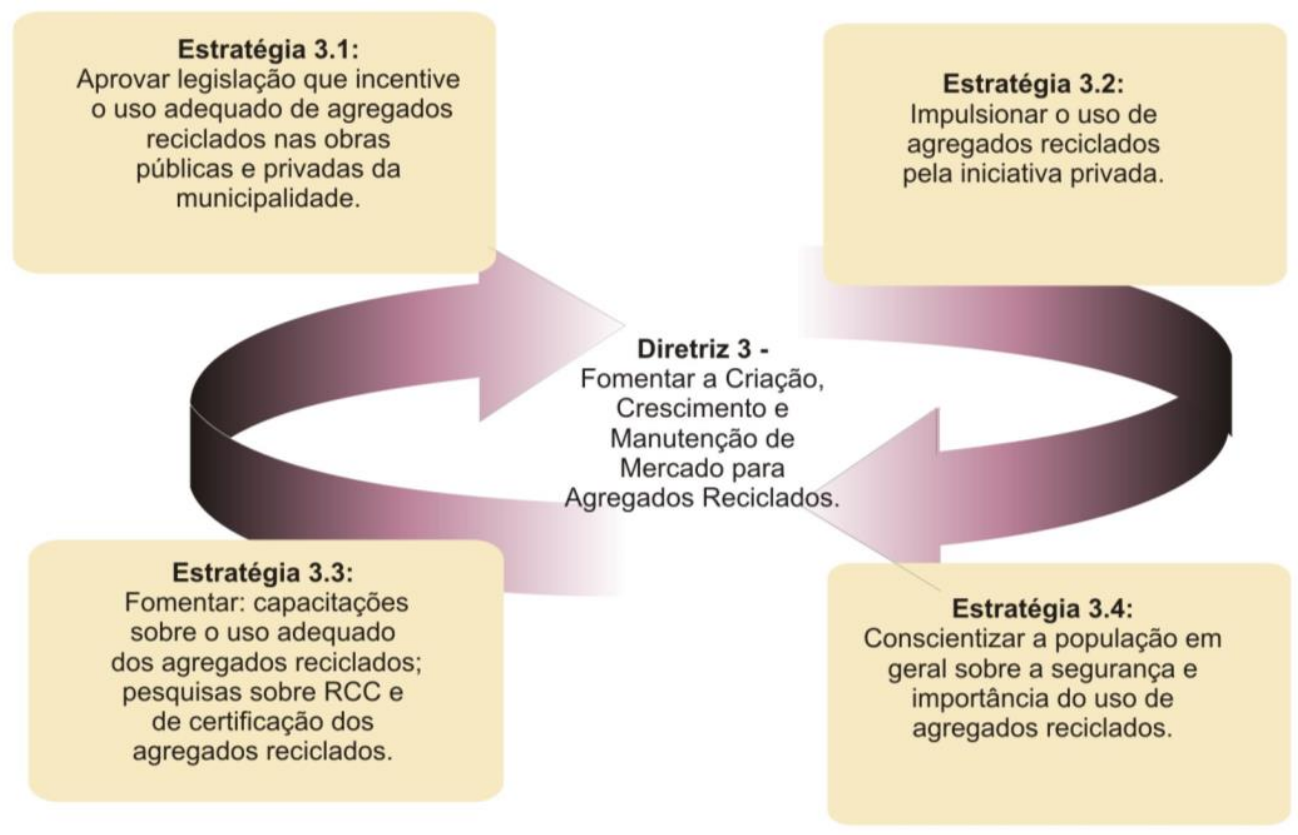

Figura 9 -Aferição das estratégias por metas da Diretriz 3 do modelo

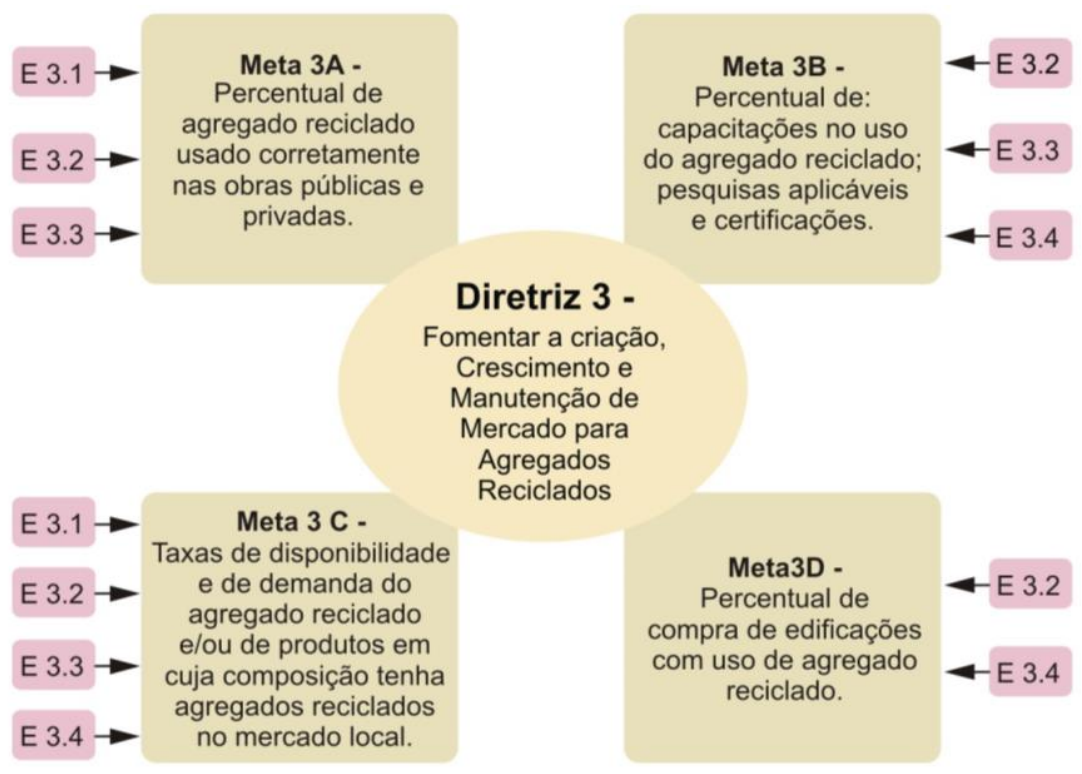

Assim, na proposição de cenários futuros, para elucidar a maturação da gestão dos RCCs proposta no modelo, a Figura 10 mostra a evolução das práticas de gestão do pequeno gerador de RCC (geralmente aquele que descarta até $1 \mathrm{~m} 3 / \mathrm{dia}$, valor definido pelo setor de limpeza municipal conforme a realidade de cada município). São mostradas quatro práticas diferentes de manejo e disposição dos RCCs.

No primeiro modo, que ainda é corrente nas municipalidades brasileiras, há a geração e o descarte clandestino (danoso e criminoso) dos
RCCs gerados. Seguindo o modelo, os resíduos serão deixados em áreas licenciadas (PEVs), que poderão fazer a separação dos resíduos por tipo (terceiro modo), o que aumentará o percentual de resíduos para a reciclagem e diminuirá os rejeitos (BRASIL, 2010).

Finalmente, após o tempo de maturação do modelo, haverá a redução, a reutilização e a segregação feita pelo pequeno gerador (quarto modo), o que reduzirá o percentual de RCC descartado nos PEVs devido à redução e à reutilização na própria fonte geradora e aumentará 
a taxa de reciclagem em relação aos rejeitos dos RCCs vindos dos PEVs.

A implantação do quarto modo como rotina do pequeno gerador também levará à drástica diminuição das deposições clandestinas, à diminuição da extração e uso de agregados virgens, e à redução do transporte, sendo esse o cenário buscado.

Na proposição de cenários futuros, para elucidar a maturação da gestão dos RCCs proposta no modelo definido, a Figura 11 mostra a evolução das práticas de gestão do grande gerador de RCC. São mostradas cinco práticas de manejo e disposição dos RCCs dos grandes geradores.

No primeiro modo, que ainda costuma ser praticado nas municipalidades brasileiras, há a geração e o descarte danoso e criminoso dos RCCs gerados pelas construtoras, que contratam grandes transportadores pelo menor preço do frete e sem a preocupação com o descarte licenciado (PUCCI, 2006; MARCONDES, 2007; LINHARES; FERREIRA; RITTER, 2007).
Em seguida, no segundo modo, há o aprimoramento com o descarte em áreas licenciadas (ATTs), que farão a triagem dos resíduos (JOHN, 2000; BRASIL, 2010), o que aumentará o percentual de resíduos para a reciclagem nas ARs e diminuirá o percentual de rejeitos.

No terceiro modo, haverá a redução da geração dos RCCs dos grandes geradores. Essa redução vem sendo ensinada em cartilhas gratuitas disponíveis (PINTO et al., 2005; CONSELHO..., 2009) e é um objetivo das construtoras, pois significa o aumento dos lucros com a diminuição das perdas de materiais e dos custos com transporte de resíduos.

Porém, devido às mudanças na cultura organizacional e nas rotinas laborais ainda presas ao paradigma da produção em linha, associado ao baixo preço dos materiais virgens e ao descarte clandestino dos resíduos (PESCI, 2004; BLUMENSCHEIN, 2009; FERNANDES; DA SILVA FILHO, 2010a), a redução dos RCCs ainda necessita de incentivos e/ou penalidades para que se estabeleça como prática corrente.

Figura 10 - Evolução das práticas do pequeno gerador
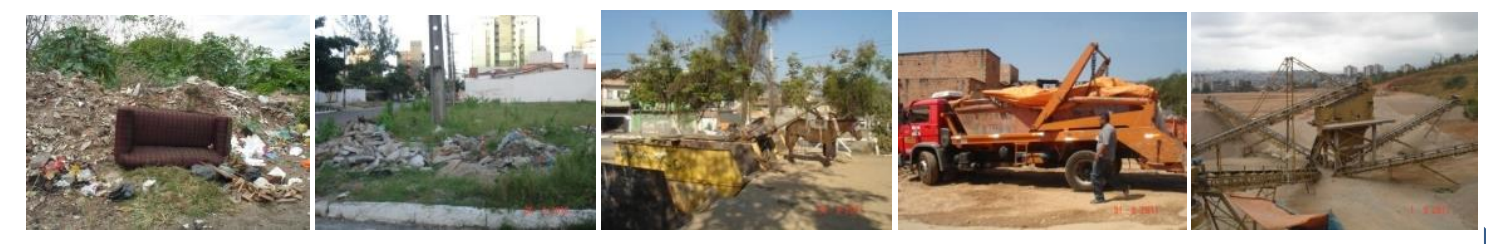

$\sum$

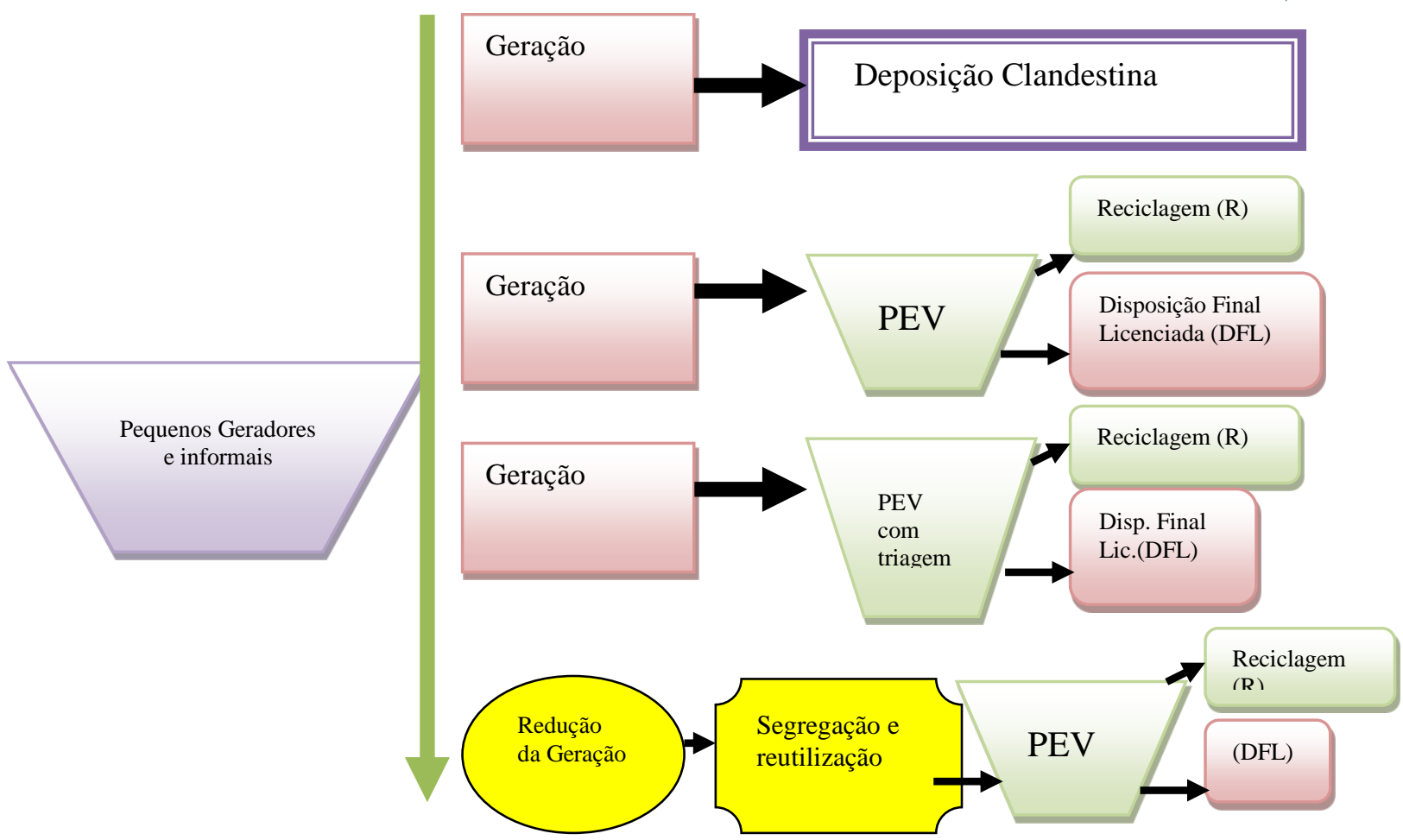


Figura 11 - Evolução das práticas do grande gerador
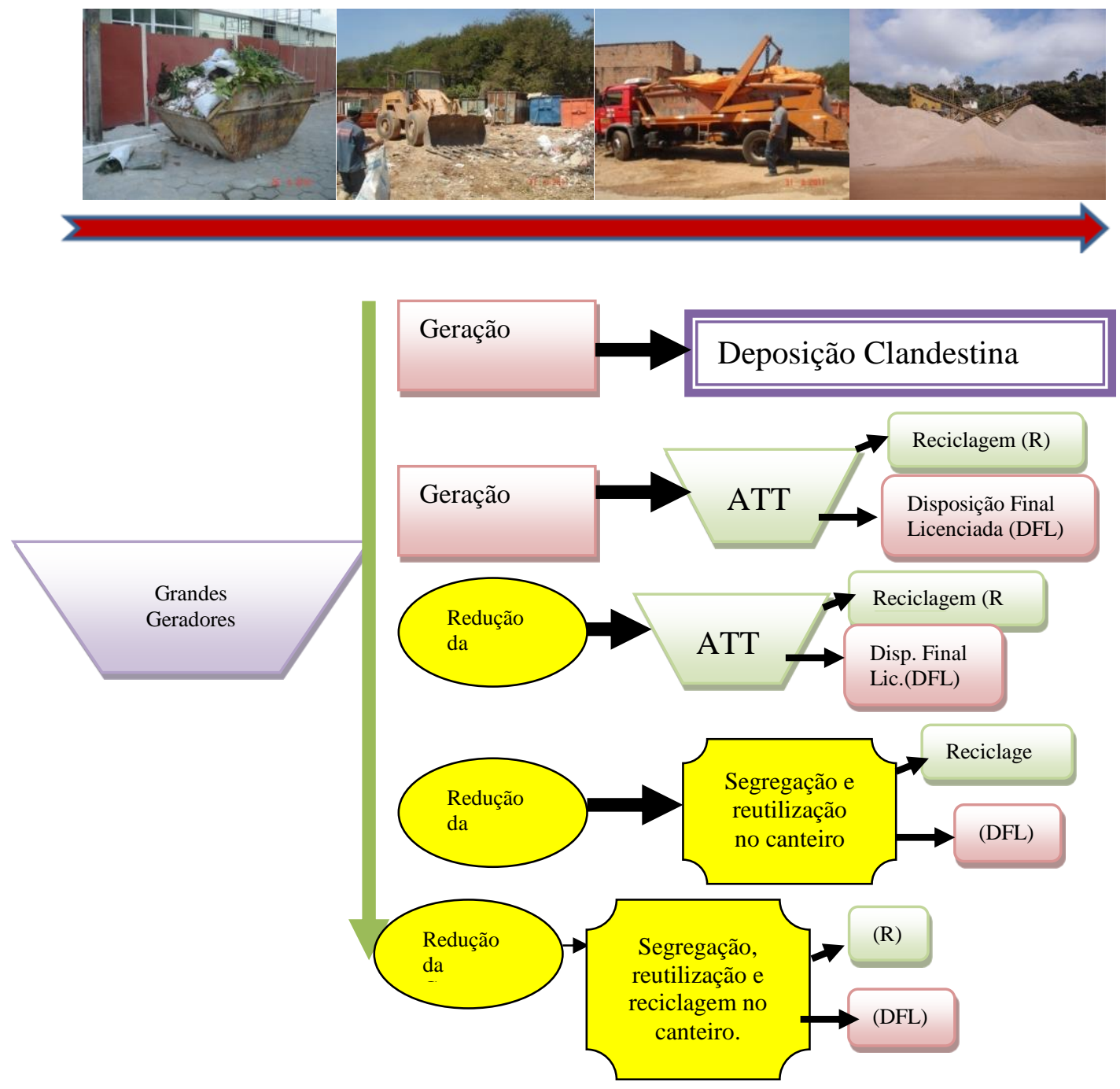

No quarto modo, haverá a redução, a reutilização e a segregação feita no próprio canteiro de obras, o que dispensará, inclusive, o transporte para a ATT (FERNANDES; DA SILVA FILHO, 2010b). Isso aumentará a proporção de reciclagem em relação aos rejeitos dos RCCs. A implantação dessa prática como rotina do grande gerador também levará à diminuição das deposições clandestinas e da saturação dos aterros licenciados, além de reduzir a extração de agregados virgens e o transporte.

Na quinta prática, a reciclagem é feita no próprio canteiro de obras com equipamentos móveis (MIRANDA, 2005; LINHARES; FERREIRA; RITTER, 2007; PASQUALOTTO FILHO et al., 2007; REMBISKI, 2012), o cenário ideal, mas nem sempre possível devido a limitações de espaço físico nas obras. Ressalta-se que, segundo Angulo et al. (2002), cerca de $70 \%$ dos custos com a reciclagem dos RCCs são decorrentes de transporte.

\section{Conclusão}

O principal desafio do presente trabalho foi reunir e sistematizar práticas, percepções, conceitos e interesses diversos e até antagônicos existentes na gestão municipal dos RCCs a fim de produzir um modelo útil e funcional que possa facilitar a implantação de uma efetiva gestão municipal desses resíduos. Nesse sentido, o primeiro desafio foi utilizar uma metodologia adequada para atender a essa complexa proposição.

Com a aplicação da metodologia SSM, os objetivos da investigação foram atingidos, a saber: identificar boas práticas na gestão diferenciada dos RCCs existentes em municípios brasileiros (cumprido nas etapas 1 e 5 da formulação do modelo); conhecer a percepção dos diferentes 
atores envolvidos na gestão desses resíduos (atingido nas etapas 1,2 e 3 da formulação do modelo) e gerar um modelo para gestão municipal dos RCCs que possa ajudar os municípios brasileiros a resolver essa demanda premente.

Com base no modelo definido, observa-se que as municipalidades estudadas apresentam importantes iniciativas pontuais, algumas como Belo Horizonte e Americana com significativa experiência consolidada, mas no geral em todas há problemas decorrentes da fragmentação da problemática e desconhecimento da figura "rica", o que leva à insatisfação de atores, que, por estarem excluídos da solução, a tornam ineficaz ou a desgastam, inviabilizando sua execução.

Nesse sentido, temos que antever, inclusive, as mudanças de percepções e interesses que possam advir nos atores envolvidos, como, por exemplo, a forte especulação imobiliária que afetou as cidades brasileiras, principalmente entre 2008 e 2014, e que foi paulatinamente cercando com edifícios a funcional, pioneira e educativa AR de Estoril, em Belo Horizonte, transformando-a no imaginário popular em "um bota-fora empoeirado!". Isso vem desencadeando uma forte pressão para seu fechamento, o que será, caso aconteça, uma perda histórica para o desenvolvimento sustentável no Brasil.

Desse modo, como o modelo definido na pesquisa reúne e estrutura boas práticas dos municípios estudados juntamente com as determinações da legislação vigente e com os anseios de pesquisadores e atores da situação estudada, espera-se ajudar os municípios brasileiros na incorporação de melhorias graduais e consistentes na gestão dos RCCs, auxiliando também os gestores na visualização de cenários futuros e no respeito ao tempo de maturação necessário à efetivação dos benefícios e ao ajuste das diferentes perspectivas dos atores envolvidos.

A metodologia SSM se mostrou adequada para a complexidade da gestão de resíduos com os diferentes e muitas vezes antagônicos interesses dos atores envolvidos. Assim, o emprego dessa metodologia, que ainda é pouco utilizada nessa área, pode ser apontado como uma das contribuições desta pesquisa, a fim de motivar o desenvolvimento de estudos de caso.

Entre as limitações da pesquisa indica-se a não implantação do modelo definido durante a investigação devido a limitações políticas (necessidade de um município que implantasse integralmente $o$ modelo definido) e, principalmente, temporais (tempo para maturação das mudanças e manifestação dos resultados), já previstas na pesquisa.
Coloca-se, ainda, a necessidade do desenvolvimento de pesquisas que abordem as parcerias público-privadas na gestão dos RCCs, que identifiquem e avaliem o lucro e os desafios do setor privado no manejo e beneficiamento dos RCCs e que façam o estudo do mercado dos agregados reciclados visando a sua consolidação e crescimento.

Em relação à aplicabilidade do modelo definido, ele pode ser utilizado nos diferentes tamanhos de municipalidades, sendo manifesta a importância de parcerias entre todos os atores envolvidos, a fim de minimizar os custos e maximizar os benefícios, principalmente no tocante aos pequenos municípios, que, pela própria legislação, são incentivados a formar consórcios intermunicipais.

Assim, embora inicialmente caiba ao poder público o papel de protagonista na implantação do modelo definido, com o tempo de maturação, o mercado de agregados reciclados se tornará um negócio forte e lucrativo, e a iniciativa privada tenderá a assumir esse filão, de tal modo que caberá ao poder público o papel de disciplinador da gestão dos RCCs, coibindo abusos financeiros, sociais, sanitários e ambientais.

\section{Referências}

ALGARVIO, D. A. N. Reciclagem de Resíduos de Construção e Demolição: contribuição para controle do processo. Lisboa, 2009. $145 \mathrm{f}$. Dissertação (Mestrado em Gestão Integrada e Valorização de Resíduos) - Faculdade de Ciências e Tecnologia, Universidade Nova de Lisboa, Lisboa, 2009.

ANGULO, S. C. et al. Desenvolvimento de Novos Mercados Para a Reciclagem Massiva de RCD. In: SEMINÁRIO DE DESENVOLVIMENTO SUSTENTÁVEL E A RECICLAGEM NA CONSTRUÇÃO CIVIL, 5., São Paulo, 2002.Anais... São Paulo, 2002.

ANGULO, S. C; JOHN, V. M. Normalização dos Agregados Graúdos de Resíduos de Construção e Demolição Reciclados Para Concretos e a Variabilidade. In: ENCONTRO NACIONAL DE TECNOLOGIA DO AMBIENTE CONSTRUÍDO, 10., Foz do Iguaçu, 2002. Anais... Foz do Iguaçu: ANTAC, 2002.

BARI, Q. H. et al. Solid Waste Recycling in Rajshahi city of Bangladesh.Journal of Waste Management, v. 32, n. 11, p. 2029-2036, 2012. 
BERNARDES, A. et al. Quantificação e Classificação dos Resíduos da Construção e Demolição Coletados no Município de Passo Fundo, RS. Ambiente Construído, Porto Alegre, v. 8, n. 3, p. 65-76, jul./out. 2008.

BRASIL. Resolução CONAMA no 307, estabelece diretrizes, critérios e procedimentos para a gestão dos resíduos da construção civil. Diário Oficial da República Federativa do Brasil, Brasília, DF, 2002.

BRASIL. 2004. Resolução CONAMA n⿳. 348, altera a Resolução CONAMA no 307, de 5 de julho de 2002, incluindo o amianto na classe de resíduos perigosos. Diário Oficial da República Federativa do Brasil, Brasília, DF, 17 de agosto de 2004.

BRASIL. 2010. Lei 12.305, que institui a Política Nacional de Resíduos Sólidos, altera a lei 9.605/98 e dá outras providências. Diário Oficial da República Federativa do Brasil, Brasília, DF, 03 de agosto de 2010.

BRASIL. 2011. Resolução CONAMA n 431, que altera o art. $3^{\circ}$. da Resolução CONAMA $n^{\circ}$. 307, de 5 de julho de 2002, estabelecendo nova classificação para o gesso. Diário Oficial da República Federativa do Brasil, Brasília, DF, 25 de maio de 2011.

BRASIL. 2012. Resolução CONAMA no 448, que altera os arts. $2^{\circ} .4^{\circ} .5^{\circ} .6^{\circ} .8^{\circ} .9^{\circ} .10^{\circ} .11^{\circ}$ da Resolução no 307 , de 5 de julho de 2002, do Conselho Nacional do Meio Ambiente-

CONAMA. Diário Oficial da República Federativa do Brasil, Brasília, DF, 19 de janeiro de 2012.

BLUMENSCHEIN, R. N. Introduzindo

Sustentabilidade na Cadeia Produtiva da Indústria da Construção. Revista Mosaico, v. 2, n. 1, p. 1725, jan./jun. 2009.

CHECKLAND, P.; POULTER, J. Learning for Action: a short definitive account of soft systems methodology and its use for practitioners. Teachers and Students. Chichester: Wiley, 2006.

CHECKLAND, P. Systems Thinking, Systems Practice. Chichester: John Wiley \& Sons, 1981.

CONSELHO REGIONAL DE ENGENHARIA E ARQUITETURA DO PARANÁ.Resíduos

Sólidos. Curitiba: CREA, 2009. Série de cadernos técnicos da agenda parlamentar.
COUTO NETO, A. G. Construção Civil

Sustentável: avaliação da aplicação do modelo de gerenciamento de resíduos da construção civil do SINDUSCON-MG em um canteiro de obras, um estudo de caso. Belo Horizonte, 2007. $100 \mathrm{f}$. Dissertação (Mestrado em Meio Ambiente, Saneamento e Recursos Hídricos) - Universidade Federal de Minas Gerais. Belo Horizonte, 2007.

CUNHA, N. A. Resíduos da Construção Civil: análise de usinas de reciclagem. Campinas, 2007. 187 f. Dissertação (Mestrado em Engenharia Civil) - Escola de Engenharia, Universidade Estadual de Campinas, Campinas, 2007.

FERNANDES, M. P. M.; DA SILVA FILHO, L. C. P. Avaliação da Gestão de Resíduos da Construção e Demolição. In: SIMPÓSIO LUSOBRASILEIRO DE ENGENHARIA SANITÁRIA E AMBIENTAL, 14.; ENCONTRO NACIONAL DE SANEAMENTO BÁSICO, 14., Porto, 2010. Anais... Porto: APESB; ABES, 2010a.

FERNANDES, M. P. M.; DA SILVA FILHO, L. C. P. Gestão de Resíduos: construção e desconstrução de conceitos no canteiro de obras. In: ENCONTRO NACIONAL DE TECNOLOGIA DO AMBIENTE CONSTRUÍDO, 13., Canela, 2010. Anais... Canela: ANTAC, $2010 \mathrm{~b}$

FERNANDES, M. P. M. Apreciação de Boas Práticas Visando à Geração de Um Modelo Para Gestão Municipal dos Resíduos da Construção Civil. Porto Alegre, 2013. 264 f. Tese (Doutorado em Engenharia Civil) - Escola de Engenharia, Universidade Federal do Rio Grande do Sul, Porto Alegre, 2013.

FREITAS, J. S.; COTA JÚNIOR, M. B. G.; CHENG, L. C. O Soft Systems Thinking e a Soft Systems Methodology: teorias, conceitos e metodologias sistêmicas. In: CONGRESSO BRASILEIRO DE SISTEMAS, 4., Franca, 2008. Anais... Franca: Centro Universitário de Franca, 2008.

JOHN, V. M. Reciclagem de Resíduos na Construção Civil: contribuição à metodologia de pesquisa e desenvolvimento. São Paulo, 2000. 113 f. Tese (Livre Docência) - Escola Politécnica, Universidade de São Paulo, São Paulo, 2000.

LINHARES, S. P.; FERREIRA, J. A.; RITTER, E. Avaliação da Implantação da RESOLUÇÃO n. 307/2002 do CONAMA Sobre Gerenciamento dos Resíduos de Construção Civil. Estudos

Tecnológicos em Engenharia, v. 3, n. 3, p. 176194, out./dez. 2007. 
MÁLIA, M. et al. Indicadores de Resíduos de Construção e Demolição Para Construções Residenciais Novas. Ambiente Construído, Porto Alegre, v. 11, n. 3, p. 65-76, jul./set. 2011.

MARCONDES, F. C. S. Sistemas Logísticos Reversos na Indústria da Construção Civil: estudo da cadeia produtiva de chapas de gesso acartonado. São Paulo: [s.1.], 2007.

MIRANDA, L. F. R. Contribuição ao Desenvolvimento da Produção e Controle de Argamassas de Revestimento Com Areia Reciclada Lavada de Resíduos Classe A da Construção Civil. São Paulo, 2005. 439 f. Tese (Doutorado em Engenharia de Construção Civil e Urbana) - Escola Politécnica, Universidade de São Paulo, São Paulo, 2005.

NUNES, K. R. A. Avaliação de Investimentos e de Desempenho de Centrais de Reciclagem Para Resíduos Sólidos de Construção e Demolição. Rio de Janeiro, 2004. 276 f. Tese (Doutorado em Engenharia de Produção) Universidade Federal do Rio de Janeiro, Rio de Janeiro, 2004.

PASQUALOTTO FILHO, R. et al. Gestão de Resíduos da Construção Civil e Demolição no Município de São Paulo e Normas Existentes. Revista Técnica IPEP, São Paulo, v. 7, n. 1, p. 55-72, jan./jun. 2007.

PESCI, R. Um Novo Humanismo e o Planejamento Ambiental. In: MENEGAT, R. et al. (Orgs.). Desenvolvimento Sustentável e Gestão Ambiental nas Cidades: estratégias a partir de Porto Alegre. Porto Alegre: Editora da UFRGS, 2004.

PINTO, T. P. Metodologia Para a Gestão Diferenciada de Resíduos Sólidos da Construção Urbana. São Paulo, 1999. 189 f. Tese (Doutorado em Engenharia Civil) - Escola Politécnica, Universidade de São Paulo, São Paulo, 1999.

PINTO, T. P. Panorama dos Resíduos da Construção Civil no Estado de São Paulo. Seminário Regional de Resíduos Sólidos. Revista Habitare, v. 5, dez. 2005.

PINTO, T. P. et al. Gestão Ambiental de Resíduos da Construção Civil a Experiência do SINDUSCON/SP: Cartilha Para Construtoras, Projeto Obra Limpa. São Paulo: SINDUSCON, 2005.
PUCCI, R. B. Logística de Resíduos da Construção Civil Atendendo à Resolução CONAMA 307. São Paulo, 2006. 137f.

Dissertação (Mestrado em Engenharia de Sistemas logísticos) - Escola Politécnica, Universidade de São Paulo, São Paulo, 2006.

REMBISKI, F. D. Análise Multimétodo de Percepções de Agentes Intervenientes na Pesquisa e no Gerenciamento de Agregados Reciclados de Resíduos da Construção Civil. Vitória, 2012. 246f.Dissertação (Mestrado em Engenharia Civil) - Universidade Federal do Espírito Santo, Vitória, 2012.

SCHNEIDER, D. M.; PHILIPPI, A. J. Gestão Pública de Resíduos da Construção Civil no Município de São Paulo. Ambiente Construído, Porto Alegre, v. 4, n. 4, p. 21-32, out./dez. 2004.

SCREMIN, L. B. Desenvolvimento de Um Sistema de Apoio ao Gerenciamento de Resíduos de Construção e Demolição Para Municípios de Pequeno Porte. Florianópolis, 2007. 152 f. Dissertação (Mestrado em Engenharia Civil) - Escola de Engenharia, Universidade Federal de Santa Catarina, Florianópolis, 2007.

SOBRAL, R. F. C. Viabilidade Econômica de Usina de Reciclagem de Resíduos da Construção civil: estudo de caso da USIBEN João Pessoa, 2012. 114 f. Dissertação (Mestrado em Engenharia Urbana e Ambiental) - Escola de Engenharia, Universidade Federal da Paraíba, João Pessoa, 2012.

TEIXEIRA, C.A.G.Jogando Limpo: estudo das destinações finais dos resíduos da construção civil no contexto urbano de Montes Claros. Montes Claros, 2010. 112 f. Dissertação (Mestrado em Desenvolvimento Sustentável) - Universidade Estadual de Montes Claros, Montes Claros, 2010.

TESSARO, A. B. et al. Quantificação e Classificação dos Resíduos Procedentes da Construção Civil e Demolição no Município de Pelotas, RS. Ambiente Construído, Porto Alegre, v. 12, n. 2, p. 121-130, abr./jun. 2012.

VALENÇA, M. Z. Understanding the Competitive Environment of Construction and Demolition Waste Management Sector in Recife, Brazil: a case study. Aberdeen, 2004. 150 f. Dissertação (MBA em Gestão Estratégica de Negócios) - Aberdeen Business School, The Robert Gordon University, Aberdeen, 2004.

ZORDAN, S. E. A Utilização do Entulho Como Agregado na Confecção do Concreto. Campinas, 1997. 156 f. Dissertação (Mestrado em Engenharia civil) - Escola de Engenharia, Universidade Estadual de Campinas, Campinas, 1997. 


\section{Agradecimentos}

À SLU e à Emlur, pelas informações e livre acesso aos locais requeridos para a coleta de dados.

À Capes.

Maria da Paz Medeiros Fernandes

Instituto Federal de Educação, Ciência e Tecnologia da Paraíba | Av. Primeiro de Maio, 720, Jaguaribe | João Pessoa - PB - Brasil | CEP 58015-435 | Tel.: (83) 3612-1200 | E-mail: pazmedeiros@bol.com.br

Luiz Carlos Pinto da Silva Filho

Departamento de Engenharia Civil, Escola de Engenharia | Universidade Federal do Rio Grande do Sul | Av. Osvaldo Aranha, $99,7^{\circ}$ andar, Centro | Porto Alegre - RS - Brasil | CEP 90035-190 | Tel.: (51) 3308-3489 | E-mail: Icarlos66@gmail.com

\section{Revista Ambiente Construído}

Associação Nacional de Tecnologia do Ambiente Construído

Av. Osvaldo Aranha, $99-3^{\circ}$ andar, Centro

Porto Alegre - RS - Brasil

CEP 90035-190

Telefone: +55 (51) 3308-4084

Fax: +55 (51) 3308-4054

www.seer.ufrgs.br/ambienteconstruido

E-mail: ambienteconstruido@ufrgs.br 